\title{
Mars Observer Camera
}

\author{
M. C. Malin, ${ }^{1,2}$ G. E. Danielson,${ }^{3}$ A.P. Ingersoll,${ }^{3}$ H. Masursky, $, 4,5$ J. Veverka,, 6 \\ M. A. Ravine, ${ }^{7}$ and T. A. Soulanille ${ }^{7}$
}

\begin{abstract}
The Mars Observer camera (MOC) is a three-component system (one narrow-angle and two wide-angle cameras) designed to take high spatial resolution pictures of the surface of Mars and to obtain lower spatial resolution, synoptic coverage of the planet's surface and atmosphere. The cameras are based on the "push broom" technique; that is, they do not take "frames" but rather build pictures, one line at a time, as the spacecraft moves around the planet in its orbit. MOC is primarily a telescope for taking extremely high resolution pictures of selected locations on Mars. Using the narrow-angle camera, areas ranging from $2.8 \mathrm{~km} \times 2.8 \mathrm{~km}$ to $2.8 \mathrm{~km} \times 25.2 \mathrm{~km}$ (depending on available internal digital buffer memory) can be photographed at about $1.4 \mathrm{~m} /$ pixel. Additionally, lowerresolution pictures (to a lowest resolution of about $11 \mathrm{~m} / \mathrm{pixel}$ ) can be acquired by pixel averaging; these images can be much longer, ranging up to $2.8 \times 500 \mathrm{~km}$ at $11 \mathrm{~m} /$ pixel. High-resolution data will be used to study sediments and sedimentary processes, polar processes and deposits, volcanism, and other geologic/geomorphic processes. The MOC wide-angle cameras are capable of viewing Mars from horizon to horizon and are designed for low-resolution global and intermediate resolution regional studies. Low-resolution observations can be made every orbit, so that in a single 24-hour period a complete global picture of the planet can be assembled at a resolution of at least $7.5 \mathrm{~km} / \mathrm{pixel}$. Regional areas (covering hundreds of kilometers on a side) may be photographed at a resolution of better than $250 \mathrm{~m} /$ pixel at the nadir. Such images will be particularly useful in studying time-variable features such as lee clouds, the polar cap edge, and wind streaks, as well as acquiring stereoscopic coverage of areas of geological interest. The limb can be imaged at a vertical and along-track resolution of better than 1.5 $\mathrm{km}$. Different color filters within the two wide-angle cameras permit color images of the surface and atmosphere to be made to distinguish between clouds and the ground and between clouds of different composition.
\end{abstract}

\section{INTRODUCTION}

Much of what is known about the state and evolution of the terrestrial planets comes from the study of images. This is particularly true for Mars. A complete list and discussion of the direct discoveries or indirect inferences of first-order importance made on the basis of photographic interpretation would fill a volume of considerable proportions. Without images, Martian craters, volcanos, channels and valleys, fretted and chaotic terrains, and polar layered deposits would be unknown, as would Martian wind streaks, dune fields, lee wave clouds, dust plumes, and localized fogs. Nearly one half of the Viking Mars Science Highlights [Solar System Exploration Committee, 1983, p. 44] refer to imaging results, clearly demonstrating that even after three previous, imaging-intensive missions, significant discoveries remained to be made by cameras. Many of these discoveries resulted from the increase in spatial resolution or temporal coverage afforded by each, more sophisticated, follow-on mission.

The Mars Observer mission offers superb opportunities to extend imaging science observations of Mars to a new level, at least an order of magnitude superior in resolution to

\footnotetext{
${ }^{1}$ Department of Geology, Arizona State University, Tempe.

${ }^{2}$ Now at Malin Space Science Systems, Incorporated, San Diego, California.

${ }^{3}$ Division of Geological and Planetary Sciences, California Institute of Technology, Pasadena.

${ }^{4}$ Branch for Astrogeology, U.S. Geological Survey, Flagstaff, Arizona.

${ }^{5}$ Deceased August 24, 1990.

${ }^{6}$ Center for Radiophysics and Space Physics, Cornell University, Ithaca, New York.

${ }^{7}$ Altadena Instruments Corporation, Pasadena, California.
}

Copyright 1992 by the American Geophysical Union.

Paper number 92JE00340.

0148-0227/92/92JE-00340\$05.00 previous Mariner and Viking data. Focused investigations, with well-defined observational goals, are possible because earlier missions provide a firm foundation upon which to build. By virtue of its position in low-altitude $(\sim 380 \mathrm{~km})$ polar orbit, Mars Observer provides a nearly ideal platform for both high-resolution imaging and synoptic observations.

The Mars Observer camera (MOC) is designed to take advantage of this opportunity. Its goals are to (1) obtain global, synoptic views of the Martian surface and atmosphere (daily at about $7.5 \mathrm{~km} / \mathrm{pixel}$ ) in order to study meteorological and climatological changes during the course of the Mars Observer mission, (2) monitor surface and atmospheric features at moderate resolution (better than 0.5 $\mathrm{km} / \mathrm{pixel}$ ) for changes on time scales of hours, days, weeks, months, and years, and at a spatial scale that permits the details of their morphological character to be discriminated, and (3) examine systematically local areas at extremely high resolution (better than $1.5 \mathrm{~m} / \mathrm{pixel}$ ) in order to quantify surface/atmosphere interactions and geological processes that operate on short time scales.

Three additional factors were critical to proposing a camera for the Mars Observer mission: (1) a dramatic increase in spatial and temporal resolution is certain to lead to new discoveries, (2) the need to provide both a global context, as well as a form of "ground truth" for remote sensing observations, and (3) the goal to provide observations directly relevant to future Mars exploration.

\section{SCIENCE Objectives}

The science objectives for the Mars Observer camera investigation fall into two broad categories: meteorology/ climatology and geoscience. Clouds, dust, variable surface features, and wind patterns are part of the former, while observations of the morphology of surface landforms (e.g., 
channels, layered deposits, etc.) and their implication for environmental phenomena (e.g., atmospheric debris transport, fluvial processes, etc.) fall within the latter category.

\section{Meteorology/Climatology}

Meteorology and climatology are intimately related, as meteorology can be regarded as the current, dynamic expression of climate. Martian meteorology is presently dominated by cyclic variations of the abundance of carbon dioxide, water, and dust within the atmosphere. Numerical models show that these cycles are influenced by such factors as topography, insolation, clouds, dust, heat transport by winds, and latent heat associated with volatile reservoirs [Toon et al., 1980; Pollack et al., 1981, 1979]. These are exactly the same factors responsible for climatic variations that occur on longer time scales, including seasonal variation in dust storm activity, seasonal growth and retreat of the polar caps, and longer-term depositional cycles, perhaps associated with variations in orbital eccentricity, obliquity, and argument of perihelion. Thus seasonal transport of water vapor offers insights into the nature of long-term sources and sinks for water in the Martian environment, and dust transport today provides important clues to sites of past as well as present deposition. Martian meteorology can vary over short time scales; hourly changes, generally associated with the passage of frontal systems, were recorded at the Viking lander sites [Tillman et al., 1979]. However, the most significant, climatologically interesting observations include phenomena persisting or occurring over periods of weeks, months, and seasons.

Clouds. Clouds are perhaps the most common and important tracer of meteorological phenomena in the Martian atmosphere [Briggs et al., 1977; French et al., 1981; Kahn, 1984]. Cloud observations provide fundamental information on global distribution and seasonal variations in atmospheric water content and saturation, especially when coupled with knowledge of atmospheric temperatures [Jakosky, 1985]. The different types of clouds and the conditions under which they form act as probes of the global, regional, and local dynamics of the atmosphere [e.g., Pirraglia, 1976]. Transport phenomena, in particular those that indicate the presence and locations of long-term sinks and sources of water, can be addressed by monitoring clouds. Clouds can, of course, also be used to infer local and regional "weather" through the movement of cloud patterns [Gierasch et al., 1979].

MOC will provide information on the global wind and dust distribution patterns, especially in the polar regions where cloud tracers are abundant. In conjunction with the pressure-modulated infrared radiometer (PMIRR) atmospheric sounding experiment that measures temperature and water vapor abundance, an estimate of transport rates will be obtained. Winds detected by tracking clouds in MOC images will generally refer to the lowest scale height of the atmosphere [Kahn, 1984] where most of the condensate clouds are found. The altitude uncertainty and the fact that the wind will be measured at only one altitude are limitations of the method. However, the temperature profiles obtained from sounding instruments will provide vertical wind profiles from thermal wind calculations. The combined data from an atmospheric sounder and the MOC should provide direct estimates of transports of heat, water, and dust to and from the polar regions.
Dust storms. There are two general types of dust storms on Mars: those that occur in relatively restricted or local environments [Peterfreund and Kieffer, 1979] and those that grow to enshroud the entire planet [Briggs et al., 1979; Zurek, 1982]. Local dust storms reflect brief periods of high winds of local or regional extent. They may also indicate differences in the type, size, and quantity of sediment available for transport. Dust devils, definitely identified in some of the highest-resolution Viking images [Thomas and Gierasch, 1985], may be the primary mechanism of raising dust from the surface. Other possible mechanisms are upslope/downslope winds, regional or global winds, and wind generated by absorption of sunlight by dust-laden atmosphere. Global dust storms develop from longer periods of wind activity and injection of dust to greater heights (permitting global transport). Dust storms are probes of Martian wind conditions during periods of activity, as they indicate wind speeds and surface roughness conditions (i.e., surface shear stress) that permit the entrainment of particulate material [Pollack et al., 1976]. Dust storms are also responsible for major seasonal albedo changes on Mars [Thomas and Veverka, 1979] and may be responsible for long-term redistribution of surface materials [Christensen, 1982].

In its global monitoring mode, MOC will catch numerous local dust storms during the dust storm season. Over periods of 10 days or more, daily maps will capture the entire life cycles of such storms. With luck, MOC images will also document the entire growth phase of a global dust storm. Anticipated results include an improved understanding of how global storms develop and spread, what conditions are necessary for their formation, and the dynamics of the dust storm front on scales of one scale height $(\sim 15 \mathrm{~km})$.

Variable surface features. Variable surface features are typically classified as streaks or splotches. Streaks are regular, long, and linear albedo patterns [e.g., Thomas et al., 1979, 1981]. Splotches are irregular areas, mostly dark or of mixed tones, found principally in or near craters or adjacent to ridges or escarpments [Thomas, 1984; Christensen, 1983]. Some splotches are clearly dune fields, but most show no specific interior morphology. Variable surface features indicate that both light and dark materials can be transported by winds [e.g., Greeley et al., 1974; Iverson and Greeley, 1984]. They are important indicators of shear stress direction at the surface (i.e., wind direction) and atmospheric stability [e.g., Veverka et al., 1981].

Several factors combine to permit MOC to provide excellent documentation of seasonal changes in and global distribution of surface albedo features at spatial scales from a few meters to several hundreds of meters, and over time scales of hours to years. Among these factors are the near-polar Sun-synchronous Mars Observer orbit, the opportunities for repetitive coverage, resolution comparable to Viking mapping images, and highly flexible mission operations capabilities internal to the instrument.

Surface volatiles in the polar regions. There are two important deposit-forming volatiles in the Martian polar regions, and each is responsible for fundamentally different phenomena. The formation and recession of the seasonal carbon dioxide polar caps represent the most important currently observable climatological phenomena on Mars. Atmospheric pressure changes associated with the waxing and waning of the carbon dioxide caps amount to as much as $25 \%$ of the total atmospheric pressure, vastly exceeding in 
magnitude diurnal and meteorological pressure waves [Tillman et al., 1979]. Much of the polar heat budget is involved with the change in phase of polar volatiles. The role of the perennial water ice caps is much less certain though probably no less important. They may act as sinks for dust and sources of water over long time scales, helping to form the polar layered sedimentary units. Currently, they represent the single largest exposures of water on Mars and are thus likely candidates for the source of water vapor seen elsewhere on the planet.

Meter-scale observations of the Martian polar regions will address two important climatological questions: (1) the detailed nature of the layers within the polar deposits and (2) the processes that form seasonal polar caps.

Since their discovery the polar layered deposits have been cited as the best evidence of cyclic climatic change on Mars. Models have been proposed linking the layers to presumed excursions of the Martian environment resulting from insolation variations associated with astronomically induced perturbations of the orbit and spin orientation of Mars [e.g., Murray et al., 1972; Cutts, 1973; Cutts et al., 1978, 1979; Toon et al., 1980]. These models have relied on limited observations of the layers, in particular their number or thickness. For example, assuming that a Martian global dust storm transports $100 \mu \mathrm{m}$ of dust to the polar cap each year, a layer about $10 \mathrm{~m}$ thick should develop in the roughly 100,000 years of each astronomical cycle. Direct measurement of the thickness of individual layers cannot be made with Mariner or Viking data, but the cumulative thickness of several tens of layers approaches $1 \mathrm{~km}$, with the computed average thickness between 10 and $30 \mathrm{~m}$. The general "order of magnitude" similarity between the global dust storm estimate and the computed thickness of each layer has been considered evidence favoring dust storm modulation by the astronomical variation as the principal mechanism for layer formation. An important test of such ideas is to determine if there are smaller layers within the deposits. Such layers, if they exist, would require significant revisions of present models.

The second question of interest is the nature of the processes responsible for the formation of the seasonal polar cap. MOC should be able to determine whether frost develops directly on the surface or if it first condenses in the atmosphere and then precipitates to the surface. It should also be able to determine the influence of small-scale topography (slopes, rocks, etc.) on the advance and retreat of the polar caps. MOC will examine representative areas adjacent to and within the polar caps and, over the course of the mission, observe these areas as they experience their seasonal cycle of frost formation and sublimation. It will provide information on patchiness, local albedo, and topography for instruments that measure bulk heat and mass fluxes into and out of the polar regions. MOC will also provide data on local wind directions from observations of "frost streaks" [Thomas et al., 1979].

Winds. The poleward transport of energy, angular momentum, carbon dioxide, water, and dust are elements essential to Martian climatology. Energy transport affects the temperatures and stability of the polar frost deposits. Angular momentum transport affects the strength of the general circulation. Transport of dust and volatiles are critical climatic processes and important controls of longterm climatic change. The common element in all atmo- spheric transport processes is wind, which can be measured by global monitoring of cloud motions.

The Mars Observer mission affords a favorable opportunity for cloud tracking. At the equator the midpoint between successive ground tracks can be viewed at an emission angle of $77^{\circ}$ and will therefore be foreshortened by a factor of 4.5 . The intrinsic resolution of the wide-angle camera $(<250$ $\mathrm{m} / \mathrm{pixel}$ at nadir) allows this foreshortening factor to be removed and still allows the surface to be sampled at better than the resolution required for cloud tracking $(5-10 \mathrm{~km} /$ pixel, see below). At higher latitudes where clouds are more abundant, the foreshortening factor is less, and there is less of a problem.

In 12 2-hour orbits (i.e., 1 Martian day), MOC can obtain measurements of winds at the 12 midpoint longitudes at all latitudes where clouds are present. For low clouds the error in velocity measurement will be close to the theoretical value of 2 pixels (about $15 \mathrm{~km}$ ) divided by the Mars Observer orbit period, or $2 \mathrm{~m} / \mathrm{s}$. For high clouds an additional error in the zonal wind velocity will occur as a result of foreshortening. A cloud $5 \mathrm{~km}$ high will appear to move eastward by $50 \mathrm{~km}$ relative to surface features, causing a spurious zonal wind of $6 \mathrm{~m} / \mathrm{s}$. A cloud $10 \mathrm{~km}$ high will have a spurious eastward speed of $12 \mathrm{~m} / \mathrm{s}$. Simultaneous estimates of cloud height by shadow measurements can be used to reduce the magnitude of this spurious wind determination.

\section{Geoscience}

Geoscience objectives are in many ways closely allied to those of meteorology/climatology. For example, the transport of sediment by winds involves the surface geology (dust deposits, sand dunes, and the like), and wind streaks depend critically on the morphology of the topographic obstacle creating the conditions necessary for their formation. The advantage that geoscientists interested in the Martian surface now enjoy is the spectacular quality of the Viking Orbiter image data set. These data permit the formulation of very specific investigations that can address fundamental questions with limited acquisition of additional data.

Channeling processes. The most obvious evidence that the environment on Mars has changed dramatically over time is found in the Martian channels and network valleys [e.g., Milton, 1973; Sharp and Malin, 1975; Pieri, 1980; Baker, 1974, 1982]. These features are believed by most investigators to be evidence of fluvial processes, which have not been active on Mars since very early in its geological evolution [Carr, 1979; Mars Channel Working Group, 1983]. However, persistent questions remain to challenge this consensus. For example, alternative fluids (e.g., wind, lava, and ice) have been invoked as being able to create the erosional forms seen in Viking and Mariner images. MOC will provide a means of testing these alternative ideas and, perhaps more importantly, allow quantitative evaluation of fluvial models. These tests derive principally from differences between the hydraulic relationships for ice, air, lava, and water. These differences are most obviously manifested in the quantity and size of the debris transported by each of these fluids. Ice can carry very large loads, both in size and quantity, and these are usually angular and unsorted. Lava rarely carries debris, and when it does, the debris is often coated with spatter and not recognizable as a separate rock type. Debris flows transport considerable material, un- 
sorted, but with distinctive size/frequency characteristics that depend on the rheology of the fluid phase. Water transports less debris, but it is much more efficient in sorting and rounding; bedforms are created that reflect the flow regime of the fluid. Wind is most effective at sorting, but it can not carry large particles. Examination of the beds, banks, and mouths of the major Martian channel systems at meter scales will provide a means of judging the nature of the debris transported by the channel-forming process and an evaluation of the mechanisms responsible.

If, as is commonly believed, the outflow channels were formed by catastrophic floods, then the size and distribution of meter-sized particles is diagnostic of flow conditions such as fluid velocity and depth. These values in turn can be used to estimate the total amount of water involved in the floods.

The small valleys and networks raise additional questions that will be addressed by MOC. The two principal alternative mechanisms for valley formation, groundwater/groundice sapping or surface runoff, can be tested by searching for specific landscape characteristics of each. For example, sapping usually proceeds by undermining of steep headwalls and sidewalls, which promotes their eventual collapse. MOC should be capable of viewing collapse features within the Martian valleys. Alternatively, runoff systems show considerable control of valley and network configuration by topography. Such control is often missing in sapping networks. Topological relationships, such as stream length to stream order ratios, can be diagnostic of fluid path, volume, and discharge.

Eolian processes. The surface/atmosphere interface acts as a particularly effective boundary condition between ephemeral processes associated with meteorology/climatology and their effects on the body of a planet [e.g., Greeley and Iverson, 1985]. Wind is the principal agent of this interaction, and an enormous wealth of information can be gleaned from direct observation of small, wind-shaped features.

Consider dunes and ripples, two types of eolian bedforms that occur at two different scales. Dunes, the larger, develop as the result of the variation of wind velocity as a function of height. They grow by perturbing the air flow, reducing the wind velocity, and depositing load. Limits on dune growth result from reshaping of the airflow streamlines by the dune itself, eventually reducing the effective drag along the dune surface and allowing as much material to be transported off the dune crest as is transported to it. The tops of dunes are thus limited to that height at which the perturbed flow regime is able to effectively transport all available material. Ripples, on the other hand, are much smaller and develop at the very base of the boundary layer as a direct consequence of the enhanced "fluid density" associated with the zone of active sediment transport. Ripples are generated by the initial perturbation of a deformable bed in response to fluid turbulence. As the perturbation grows, its effects propagate downflow in a self-replicating (and energy conservative) manner depending on the many characteristics of the fluid (e.g., velocity, viscosity, etc.). Once formed, ripples move by a combination of saltation-induced reptation, saltation impact dislodgement, and fluid pressure. Their motion is analogous to that of dunes, with steep leeward slip faces formed by avalanching, and shallow windward faces modified by the impact processes and fluid pressure.

Spacing, height, transverse length, and transverse sinuos- ity of both dunes and ripples are critically dependent on particle size, particle abundance, wind speed, and wind direction constancy. Measurements of the planimetric spatial attributes of bed forms, especially those that depend mostly on particle size (e.g., on such bed forms as granule or gravel ripples), will provide details on the fluid and particle properties in different Martian environments. Such analyses will be used to calibrate remote thermal (Mars Observer) and microwave (Earth based) observations.

Volcanic processes. Volcanism has played a preeminent role in the evolution of the Martian surface [e.g., Carr, 1973; Carr et al., 1977a]. Volcanic constructs around central vents and fissures can be discriminated in Mariner and Viking images. Volcanism is a major surface manifestation of the thermal evolution of a planet, and effects that accompany volcanism can greatly affect the planetary environment, for example, as volatiles are outgassed to create an atmosphere.

Surface morphology of volcanic flows provides information to constrain modes of emplacement and temperatures and viscosity of the molten rock [e.g., Hulme, 1974; Moore et al., 1978]. For example, surfaces with aa texture are developed when flows have experienced a specific transition in rheological properties, usually engendered by turbulence associated with the descent of steep slopes, crystallization within the magma, or devolatilization. The observation of such transitions, combined with measurements of flow cross section and regional slopes, can be used to calculate rheological behavior using models for lava flows based on terrestrial studies. Chemical and mineralogical compositional estimates derived from gamma ray and thermal emission spectrometer (TES) observations, slope measurements from the laser altimeter, and surface morphology should place strong constraints on magma petrogenesis.

Canyon-forming processes. Since their discovery in Mariner 9 images, the canyons of the Valles Marineris have been recognized as affording a unique opportunity to examine both the most ancient and the most recent aspects of Mars [Sharp, 1973; Blasius et al., 1977]. Penetrating as deep as $10 \mathrm{~km}$ beneath the surrounding surface (which may exceed 3.5 billion years in age), the canyon walls reveal layering reflecting the most ancient rocks to be found on Mars [e.g., Malin, 1976]. Layered deposits, some standing as high above the canyon floors as the surrounding walls, could be pyroclastic [Peterson, 1981] or lake sediments [McCauley, 1978] dating back to Mars' early history. Yet fresh fault scarps, truncated spurs, uncratered landslide deposits beneath fresh-looking scars, and possibly recent volcanic deposits on the floors and walls of the canyons attest to current activity [Sharp, 1973; Lucchitta, 1978].

MOC observations will address the nature and time scale of canyon formation. High-resolution images of scarp brinks will reveal details of the material response to mass movement, while similar images of fault scarps will allow assessment of the "diffusion" of material away from these scarps (a measure of their "age'). The nature of sedimentary materials within the canyons should be clearly delineated in MOC images.

Cratering. Craters are the single most useful probes of planetary surfaces. They reveal important information about rock properties, erosional processes, and many levels of time relationships. The size and abundance of craters are strongly dependent on factors directly related to the Martian 
environment: small crater populations reflect the complex interaction between primary influx, atmospheric filtering of incoming bodies, and surface processes. The smaller the crater, the shorter the time scale. Therefore the small craters provide a sensitive measure of recent Martian geologic evolution. Material properties are believed to play important roles in determining what an impact crater and its ejecta will look like after emplacement. For example, flow-ejecta craters may reflect the influence of free, frozen, or otherwise bound volatiles on ejecta distribution [Carr et al., 1977b; Mouginis-Mark, 1979]. The size, number, and sorting of debris associated with both impact cratering and with debris flows are characteristic of the emplacement mechanism. Detailed observation of this debris could discriminate between ballistic distribution combined with atmospheric effects and debris flow mechanisms.

Mass movements and other geological flows. Surface features on geological flows, such as the size of boulders carried by a debris flow, can be used to place constraints on their rheological behavior. These constraints include the amount of interstitial fluid required to mobilize the debris. Studies of debris aprons around fretted terrains in Deuteronilus, Nilosyrtis, and Protonilus and around massifs bounding the Argyre and Hellas basins show, in the best Viking images, subtle evidence of longitudinal streaking that may indicate levees or other features associated with mass movement phenomena. Unfortunately, in Viking images, these features remain unresolved. MOC images should allow alternative emplacement models for the fretted terrain aprons to be assessed.

\section{Future Mars Mission Objectives}

Mars exploration has been, and is most likely destined to continue to be, a major focus of the U.S. planetary program. Perhaps the biggest problem facing future surface exploration of Mars is the enormous difference between what is seen in available orbiter images and what is actually found on the ground. Orbital views of the Viking landing sites in no way resemble the views seen by the landers. It is unlikely that vehicles will be sent to the surface of Mars until it is certain that they can land and conduct their experiments safely and profitably. On the Moon the Apollo program was preceded by Ranger, Lunar Orbiter, and Surveyor. While Surveyor demonstrated landings could be made, it was Lunar Orbiter that provided the data necessary to permit safe manned operations.

The Mars Observer camera is designed with a number of engineering capabilities in mind, most important of which is the ability to image features on the surface with dimensions comparable to or less than those of surface vehicles. One specific objective is to image the Viking landers, in order to provide a specific test of these capabilities. Additionally, other areas of interest as potential landing sites have been, and will be, selected for similar scrutiny.

\section{ObSERVATIONAL REQUIREMENTS}

\section{Meteorology/Climatology}

For some of the objectives listed above, the requirement is to map the entire globe in 1 day at low resolution $(\leq 10$ $\mathrm{km} /$ pixel). For other objectives the requirement is to map selected regions at medium $(\sim 0.5 \mathrm{~km} /$ pixel) and high $(\sim 1.5$ $\mathrm{m} /$ pixel) resolution. Studying the same place at different times is important for meteorology/climatology objectives, since the detection of motion and change is essential to characterizing atmospheric processes.

Regional weather patterns are large scale and rotate with the planet. In a day, uniform sampling in longitude over the entire globe enables the separation of longitudinal averages from local eddies and estimation of the contribution of each to global transport. Maps acquired every 10-20 days allow studies of meteorological variability as well as longer-term (seasonal) trends. The observational requirement adopted for the MOC is to globally monitor, on a daily basis, clouds, hazes, winds, dust, and surface albedo patterns on scales better than the atmospheric scale height of about $15 \mathrm{~km}$.

The observational requirement for cloud-tracked wind observations is that the projected distance of one pixel be no more than one half the desired accuracy of the wind measurement times the interval between measurements. It has been demonstrated that this is a valid requirement both by comparing cloud-tracked wind measurements with in situ measurements in atmospheres where small-scale clouds exist [e.g., Belton et al., 1976; Limaye and Suomi, 1981; Schubert, 1983] with zonal winds derived from the pressure field by the radio occultation technique [Newman et al., 1984] and by comparing cloud-tracked winds observed at a variety of scales [Ingersoll et al., 1981; Limaye et al., 1982]. With a time interval of 2 hours (the Mars Observer orbit period) and a velocity accuracy of $2 \mathrm{~m} / \mathrm{s}$, the required resolution at Mars is $7.2 \mathrm{~km} / \mathrm{pixel}$. Studies of Mariner 9 and Viking Orbiter images [e.g., Kahn, 1984] reveal that smallscale clouds are sufficiently common on Mars, particularly at certain latitudes and seasons, to support such investigations.

Daily global monitoring over periods of several weeks when dust storms are expected should capture the life cycle of several storms of moderate size and perhaps a global dust storm. Polar cap recession rates average about $1 \mathrm{~km} /$ day, but the polar cap edge is irregular and shows the effects of topography and other surface properties. Identifying the processes that control polar cap recession requires images on the scale of the topography and surface heterogeneities. There is no single scale for these variations, but other instruments on the Mars Observer mission (TES and PMIRR) will be mapping the surface at a few to $10 \mathrm{~km}$ resolution. The requirement for imaging the polar cap edge is therefore to match or exceed the resolution on which surface properties are measured by other instruments. Medium resolution targeting of the polar cap edge on several successive days is required to reveal changes on scales of $1 \mathrm{~km} /$ day.

Other phenomena, such as the polar hood, lee wave clouds, surface wind streaks, and certain fogs and hazes, occur at certain well-defined times and places. These phenomena have not been monitored on a daily basis. Little is known about day-to-day variability, correlation with passing weather systems, and dependence on humidity, dust activity, or wind speed. The observational requirement is to perform such monitoring at specific locations at medium resolution several times during the Mars year.

\section{Geoscience}

The resolution necessary to address many geoscience issues discussed above depends to a large measure on the certainty with which one wishes to obtain definitive data and 


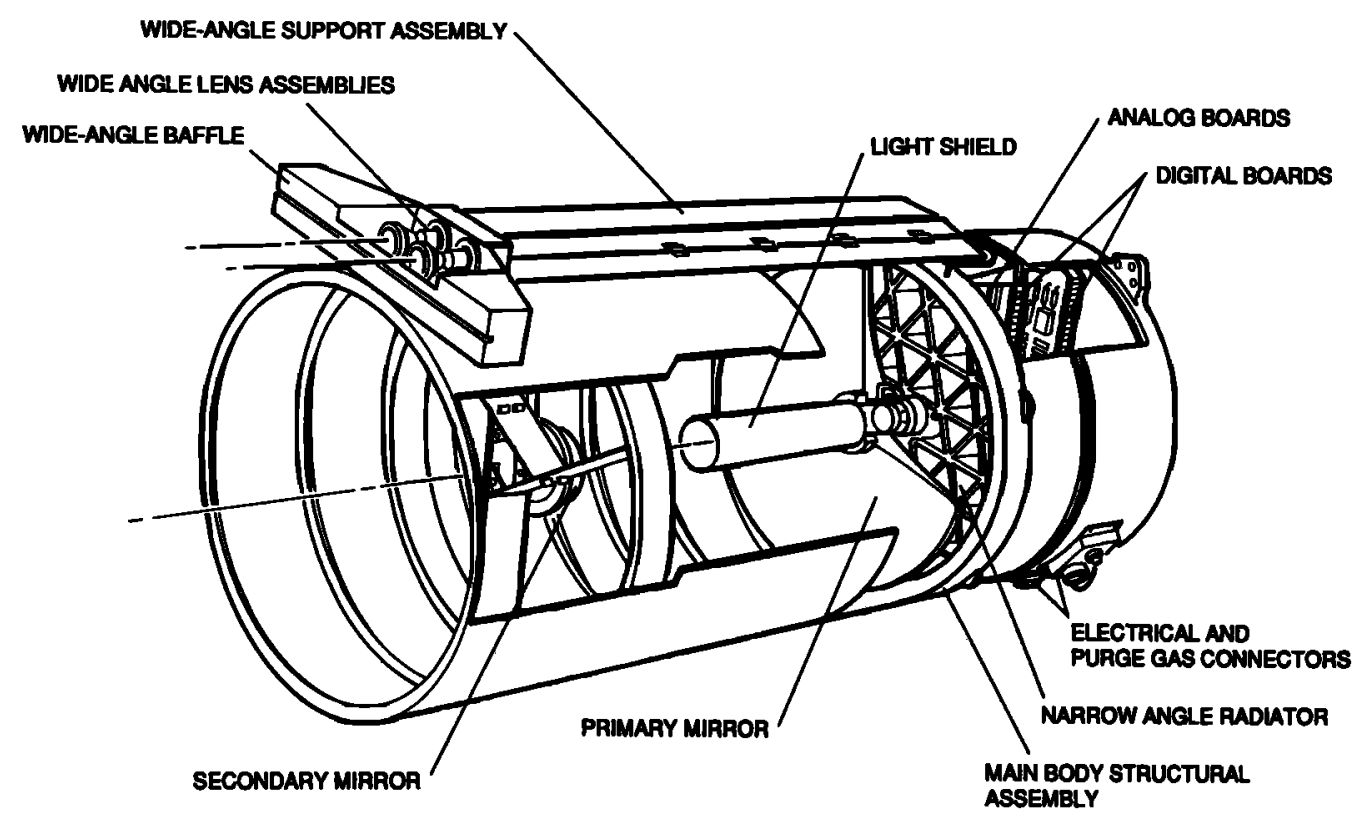

Fig. 1. Technical drawing of Mars Observer camera.

on the scale and time scale under examination. Most of Mars was covered by Viking orbiters at a resolution of about 200 $\mathrm{m}$, large fractions were imaged at resolutions between 50 and $200 \mathrm{~m}$, and only a very small fraction was observed at higher resolution (approaching $10 \mathrm{~m}$ ). In order to address processes with sedimentological and stratigraphic relationships, even higher resolution is required. To address time scales of 100,000 to $1,000,000$ years requires resolution more comparable to terrestrial aerial photography. A representative resolution for such imaging would be near $1 \mathrm{~m} / \mathrm{pixel}$. It is impractical today to cover much of Mars at $1 \mathrm{~m} /$ pixel. Fortunately, it is not necessary to do so. One of the lessons learned from Viking high-resolution images is that contiguous swaths of extremely high-resolution data do not show large changes from frame to frame. Thus at high resolution a representative area is all that is needed. Similarly, Viking high-resolution coverage showed that one could not predict on the basis of "normal" Viking resolution what would be seen at the highest resolution. Thus a judicious sampling program, combining elements of random selection with elements of uniform coverage and occasional targeting, has the best chance of solving many of the problems outlined above.

\section{Instrument Functional Requirements}

The observational requirements outlined above lead directly to specific measurement objectives. The $1.5 \mathrm{~m} / \mathrm{pixel}$

TABLE 1a. Performance Parameters for Each Component of the Mars Observer Camera

\begin{tabular}{|c|c|c|c|}
\hline & \multicolumn{3}{|c|}{ Component } \\
\hline & Narrow-Angle Assembly & $\begin{array}{c}\text { Wide-Angle Assembly, } \\
\text { Red Band Pass }\end{array}$ & $\begin{array}{c}\text { Wide-Angle Assembly, } \\
\text { Blue Band Pass }\end{array}$ \\
\hline Focal length & $3.5 \mathrm{~m}$ & $11.0 \mathrm{~mm}$ & $11.4 \mathrm{~mm}$ \\
\hline Aperture/entrance pupil* & $0.35 \mathrm{~m}$ & $1.7 \mathrm{~mm}$ & $1.8 \mathrm{~mm}$ \\
\hline Focal ratio & $f / 10$ & $f / 6.4$ & $f / 6.3$ \\
\hline Angular field of view & $7.7 \mathrm{mr}\left(0.44^{\circ}\right)$ & $2.44 \times\left(140^{\circ}\right)$ & $2.44 \times\left(140^{\circ}\right)$ \\
\hline Instantaneous field of view & $3.7 \mu r\left(0.76^{\prime \prime}\right)$ & $0.64 \mathrm{mr}\left(2.2^{\prime}\right)$ & $0.61 \mathrm{mr}\left(2.1^{\prime}\right)$ \\
\hline Resolution at $380 \mathrm{~km}$ & $1.41 \mathrm{~m} /$ pixel & $242 \mathrm{~m} /$ pixel & $233 \mathrm{~m} /$ pixel \\
\hline Swath width (pixels) & 2048 & 3456 & 3456 \\
\hline Swath width at $380 \mathrm{~km}$ & $2.9 \mathrm{~km}$ & $\operatorname{limb}+80 \mathrm{~km}$ to $\operatorname{limb}+80 \mathrm{~km}$ & $\operatorname{limb}+80 \mathrm{~km}$ to $\operatorname{limb}+80 \mathrm{~km}$ \\
\hline Signal-to-noise ratio & $\begin{array}{l}\text { 20:1 for } A \sim 0.1, i \sim 70^{\circ} \text {, at } \\
\text { aphelion }\end{array}$ & $\begin{array}{l}20: 1 \text { for } A \sim 0.1, i \sim 80^{\circ}, \text { at } \\
\text { aphelion }\end{array}$ & $\begin{array}{l}20: 1 \text { for } A \sim 0.1, i \sim 80^{\circ} \text {, at } \\
\text { aphelion }\end{array}$ \\
\hline CCD readout noise & $<50$ electrons at $-20^{\circ} \mathrm{C}$ & $<30$ electrons at $-20^{\circ} \mathrm{C}$ & $<30$ electrons at $-20^{\circ} \mathrm{C}$ \\
\hline Line time & $0.44 \mathrm{~ms}$ & $75 \mathrm{~ms}$ & $75 \mathrm{~ms}$ \\
\hline Radiometric accuracy & $<10 \%$ absolute, $<3 \%$ relative & $10 \%$ absolute, $3 \%$ relative & $10 \%$ absolute, $3 \%$ relative \\
\hline Spectral band pass & $500-900 \mathrm{~nm}$ & $575-625 \mathrm{~nm}$ & $400-450 \mathrm{~nm}$ \\
\hline $\begin{array}{l}\text { Geometric accuracy } \\
\text { System MTF }\end{array}$ & $\begin{array}{l}\text { better than } 2 \% \\
>0.1 \text { at all frequencies below }\end{array}$ & $\begin{array}{l}\text { better than } 2 \% \\
>0.1 \text { at all frequencies below }\end{array}$ & better than $2 \%$ \\
\hline Dystem in to & Nyquist (38.5 line pairs/mm) & Nyquist (71.4 line pairs/mm) & Nyquist (71.4 line pairs $/ \mathrm{mm})$ \\
\hline
\end{tabular}

*Aperture pertains to narrow-angle assembly; entrance pupil pertains to wide-angle assemblies. 
TABLE 1b. Other Information for the Mars Observer Camera

\begin{tabular}{|c|c|}
\hline & Value \\
\hline Mass & $\begin{array}{l}23.6 \mathrm{~kg} \text { (including redundant } \\
\text { electronics) }\end{array}$ \\
\hline Power & $\begin{array}{l}6.7 \mathrm{~W} \text { standby, } 9.5 \mathrm{~W} \text { acquiring } \\
\text { wide angle only, } 18.7 \mathrm{~W} \text { when } \\
\text { acquiring narrow angle }\end{array}$ \\
\hline Physical dimensions & $\begin{array}{l}\text { 88-cm-long by } 40 \text {-cm-diameter } \\
\text { cylinder }\end{array}$ \\
\hline Data rates & $\begin{array}{l}0.7,2.856,9.12 \mathrm{kbit} / \mathrm{s} \text { (record only); } \\
29.26+1.388,4.52,10.782 \mathrm{kbit} / \mathrm{s} \\
\text { (real time }+ \text { record) }\end{array}$ \\
\hline Processor speed & $\begin{array}{l}10 \mathrm{MHz}, \sim 1 \text { million instructions } / \mathrm{s} \text {, } \\
\text { 32-bit word }\end{array}$ \\
\hline $\begin{array}{l}\text { Dynamic random access } \\
\text { memory image buffer } \\
\text { memory }\end{array}$ & 12 Mbytes \\
\hline SRAM operational memory & 192 kbytes \\
\hline $\begin{array}{l}\text { UV-EPROM program } \\
\text { memory }\end{array}$ & 124 kbytes \\
\hline Data compression & $\begin{array}{l}\geq 1.5: 1 \text { for predictive lossless } \\
\text { compression; } \geq 5: 1 \text { with transform } \\
\text { compression with loss }\end{array}$ \\
\hline Bit error rate & $\begin{array}{l}\text { Mars Observer camera contribution } \\
<10^{-6}\end{array}$ \\
\hline
\end{tabular}

SRAM is static random access memory; EPROM is erasable programmable read-only memory. resolution goal for the MOC narrow-angle camera optical design was established as a compromise between engineering considerations (principally mass and size constraints) and science observational objectives likely to provide diagnostic information on geological phenomena of extreme interest. Among the latter were (1) the search in the polar layered terrains for layers smaller than those resolved by Viking and Mariner 9, (2) the assessment of sediment transported during channel-forming events (several phenomena have power law and lognormal boulder size-frequency relationships that can be differentiated at resolutions of less than $2 \mathrm{~m} / \mathrm{pixel}$, (3) the search for landforms diagnostic of ground water or ground ice processes (also in the $2 \mathrm{~m} / \mathrm{pixel}$ size range), (4) search for evidence of recent localized volcanic activity, and (5) characterization of the Viking Lander sites at a scale that permits lander and orbiter images to be compared. This characterization will be achieved only if sufficient targeting capability and ground track spacing control is available.

It was decided that the wide-angle camera field of view must extend from limb to limb, with approximately $80 \mathrm{~km}$ margin at each limb. This led to the selection of extremely short focal lengths. The desire to image in two color bands further required optimization of focal length/focal ratio.



Fig. 2. Functional block diagram of Mars Observer camera. 

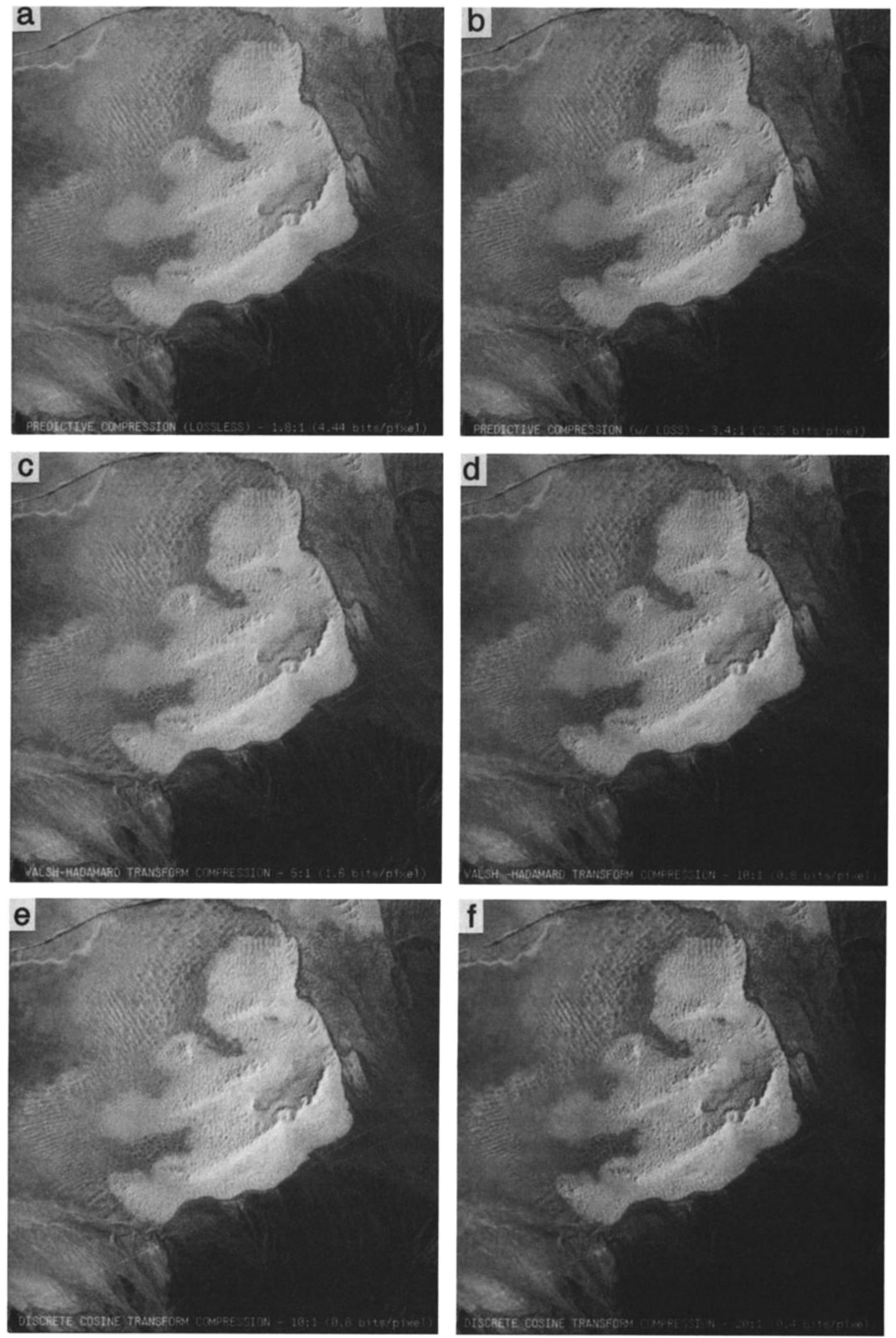
TABLE 2. Mars Observer Camera Development Team

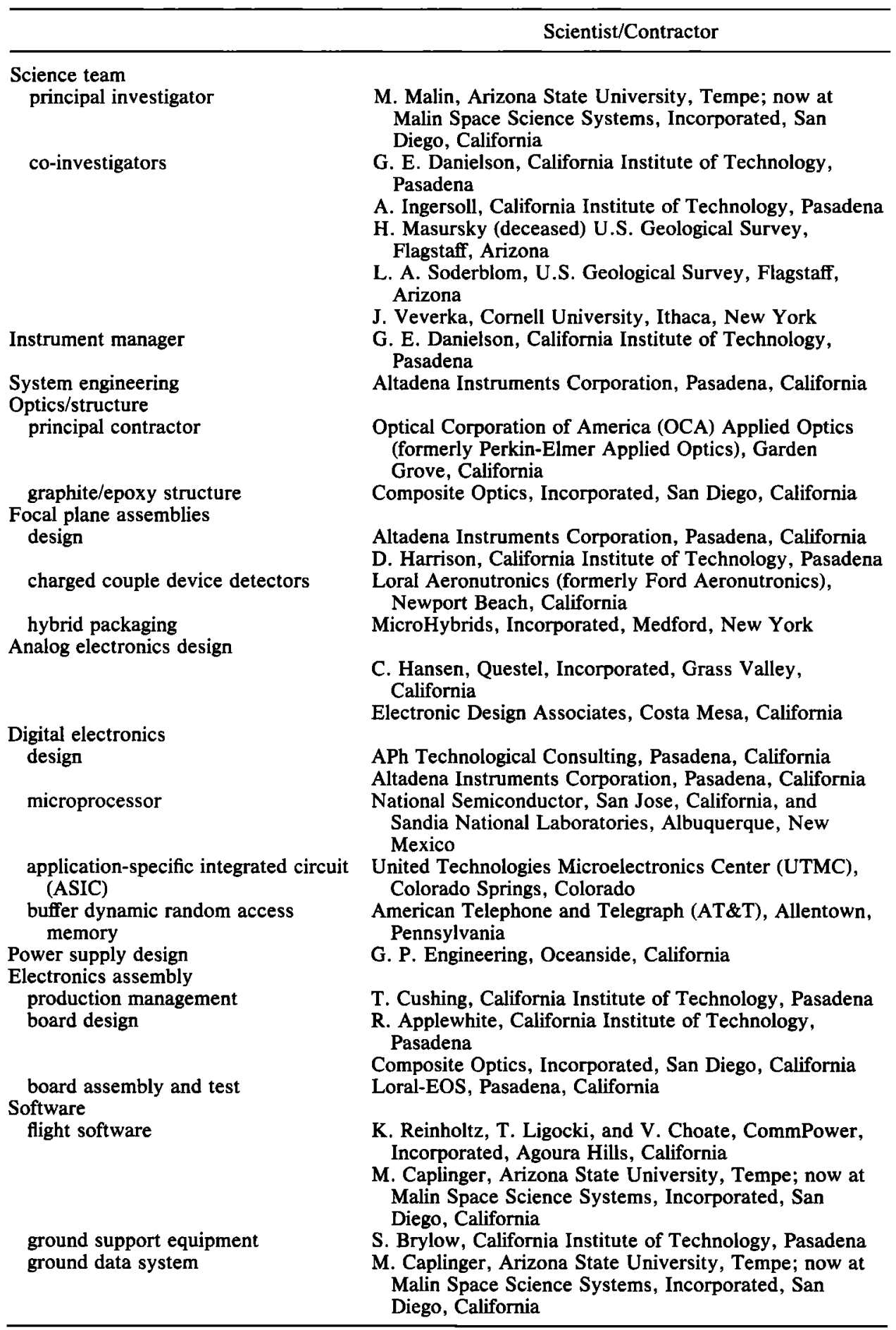

In order to interpret MOC images, a minimum signal-tonoise ratio (SNR) of 20:1 was required for a narrow-angle target of albedo $(A)$ equal to 0.10 at an illumination angle $(i)$ of $70^{\circ}$, and for a wide-angle target of $A=0.10$ at $i=85^{\circ}$, for

Fig. 3. (Opposite) Example of data compression techniques to be employed on Mars Observer camera (Landsat thematic mapper 5/1138/17/45 band 1 partial frame): (a) lossless predictive ( $1.8: 1) ;(b)$ lossy predictive $(3.5: 1)$; $(c)$ Walsh-Hadamard $(5: 1)$; $(d)$ WalshHadamard (10:1); $(e)$ discrete cosine (10:1); and $(f)$ discrete cosine (20:1).
Mars at aphelion. In order to achieve the required spatial resolutions of better than $1.5 \mathrm{~m} /$ pixel (narrow angle) and 250 $\mathrm{m} /$ pixel (wide angle), the system modulation transfer functions had to exceed 0.10 at all spatial frequencies below the Nyquist limit.

To match the low data rates available to the Mars Observer spacecraft data system, a buffer sufficient to hold several images was needed. As a design point, it was decided that the MOC should be able to acquire one $2048 \times 2048$ image while a second was being compressed and/or trans- 


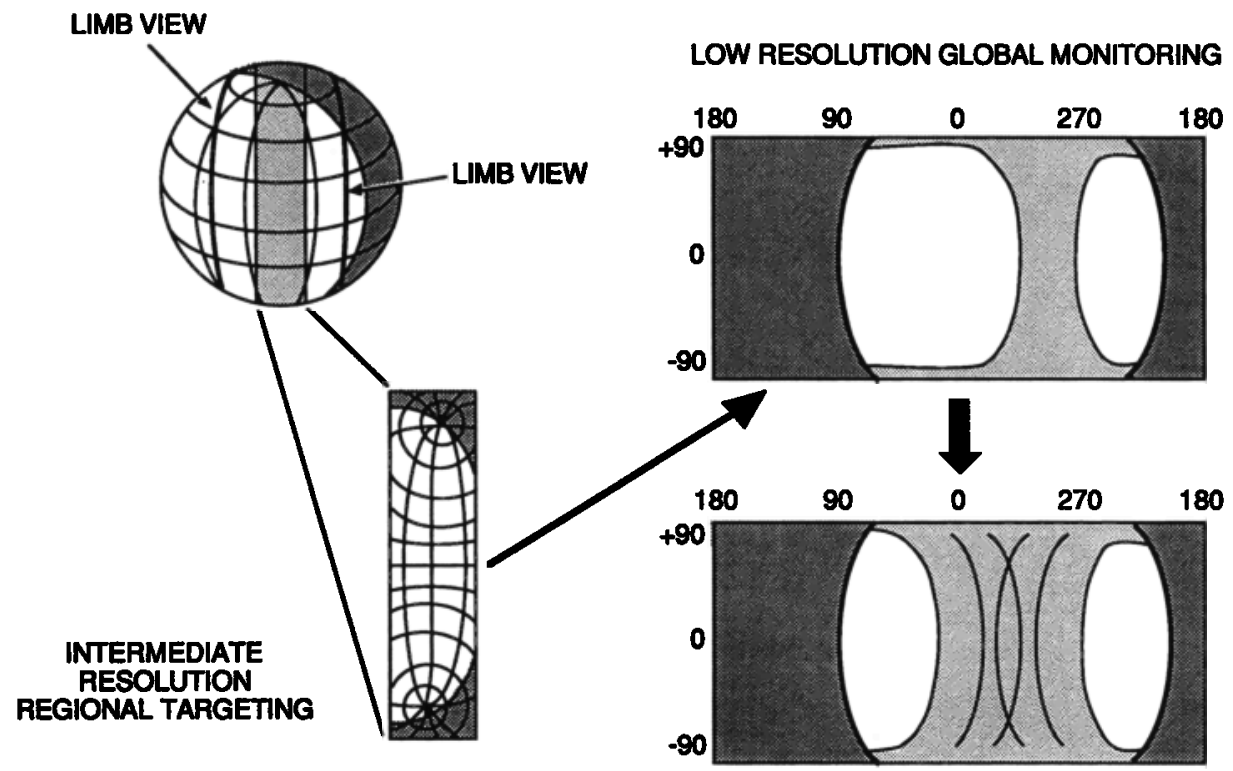

Fig. 4. Schematic representation of the construction of global map from repetitive wide-angle observations. Only the center half of the field of view is used to construct the global map. Owing to seasonal and orbital constraints, neither the ground track nor the terminator align with areocentric longitude, and portions of one pole or the other will be in shadow at any given time. Every roughly 2 hours a new swath will be acquired and added to the previous swaths, after proper geometric correction.

mitted to the spacecraft data system. Approximately 1.5 megabytes (MB) of memory is needed for software and sequencing, and a margin of about $25 \%$ is needed to assure adequate memory survives the mission. The total buffer size was set at $12 \mathrm{MB}$.

\section{INSTRUMENT DESCRIPTION}

\section{Instrument Design}

MOC consists of a single structure approximately $88 \mathrm{~cm}$ in length and $40 \mathrm{~cm}$ in diameter that includes three major components (Figure 1). The principal component of the camera is the narrow-angle (NA) optics/structure, composed of graphite/epoxy. Below the NA mirror is the electronics assembly, housed within an aluminum chassis/radiator assembly. Attached to the side of the NA structure are the wide-angle (WA) cameras, consisting of a combined mechanical support and their individual optics and focal planes. Each of the three sets of optics (two very short focal length "fish-eye"' lenses and a very long focal length telescope) has its own charge-coupled device (CCD) line array detector. The camera is fixed on the nadir panel, pointing down toward Mars; it has no independent pointing capability. Table 1 outlines the important physical and electronic characteristics of the instrument.

MOC cameras are of the "push broom" type, which means that spacecraft motion generates the image by "pushing" the line arrays, oriented perpendicular to the velocity and nadir vectors, along the ground track. The cross-track dimension of the image is defined by the length of each CCD detector and the focal length of the optics, while the along-track dimension is defined by the length of time the detectors are active. The $\sim 3$ $\mathrm{km} / \mathrm{s}$ ground track velocity and the focal length of the optics determine the line exposure time: 0.44 milliseconds ( $\mathrm{ms}$ ) for the narrow angle system and $75 \mathrm{~ms}$ for the wide angle systems. The cameras are electronically shuttered (i.e., the accumulated charges are shifted from the $\mathrm{CCD}$ in the time required to advance one resolution element)

The NA system is a $35-\mathrm{cm}$ aperture, $3.5-\mathrm{m}$ focal length ( $f / 10)$ Ritchey-Chretien telescope, filtered to operate in the 500- to 900 -nm band pass. A $2048 \times 1$-element line array with $13-\mu \mathrm{m}$ pixels provides $1.41 \mathrm{~m} / \mathrm{pixel}$ at $380-\mathrm{km}$ altitude and better than $1.5 \mathrm{~m} /$ pixel over the entire range of operational altitudes. The WA system consists of two cameras, one optimized in the 400- to 450-nm ("blue') band pass and the other in the 575- to 625-nm ("red") band pass. The blue WA camera $(f / 6.3)$ has a focal length of $11.4 \mathrm{~mm}$, while the red WA camera $(f / 6.4)$ has a focal length of $11.0 \mathrm{~mm}$. Both cameras use a $3456 \times 1$-element line array with $7-\mu \mathrm{m}$ pixels, achieving nadir resolutions of $230 \mathrm{~m} /$ pixel (blue) and 235 $\mathrm{m} /$ pixel (red) from $380-\mathrm{km}$ altitude.

The MOC electronics are block redundant, with each completely independent "half-system" consisting of a 32-bit microprocessor (Sandia SA 3300) operating at $10 \mathrm{MHz}$ and $\sim 1$ million instructions per second (MIPS), a 12-MB buffer consisting of 96 1-Mbit (Mb), 120-ns dynamic random access memory (DRAM) chips, and three 11,000-gate and one 8000-gate application-specific integrated circuits ("gate arrays") operating on 50-ns clocks. The block redundant half-systems are cross-strapped to allow operation of the NA and both WA cameras by either set of electronics. All three cameras can operate simultaneously. The functional block diagram is shown in Figure 2.

Each system uses custom CCDs that, along with their associated analog electronics, provide the low-noise performance necessary to meet the signal-to-noise requirements. The NA camera system noise is less than 50 electrons at its nominal operating speed of 5 million pixels per second. The WA camera system noise is less than 30 electrons at $\mathbf{5 0 , 0 0 0}$ pixels per second.

MOC has considerable capabilities to compress images to 




Fig. 5. Typical coverage and resolution of a wide-angle regional view (resolution $\sim 250 \mathrm{~m} /$ pixel, image $\sim 2000 \times$ 2000 pixels). This image consists of four Viking Orbiter images (VO 084A10 through VO 084A13). Small arrow indicates location of Figure 9.

optimize on-board storage and downlink utilization. Three different forms of compression are available. During acquisition of images (i.e., in real time) a predictive compression technique can be employed, in either lossless or "lossy" form, to acquire more data than would otherwise fit in the MOC buffer. The predictive compression is implemented in hardware for the NA camera, and the same algorithm can be applied in software to the WA. Lossless compression factors from 1.5 to 2.5 are possible; with loss the factors are larger, but image quality is degraded, primarily by contouring that results from insufficient bits to represent the actual image gray levels. Once data are in the buffer, they can be compressed (decompressed and then recompressed if previously compressed) using two transform compression techniques: Walsh-Hadamard (WH) and discrete cosine (DC). WH compression can be used to compress images when time is critical, as it is somewhat faster than the DC transform. Compression factors of 3-5 are possible with acceptable degradation (mostly in the form of "blockiness" associated with the loss of high-frequency information). DC provides the highest compression factors with the least degradation, but it is also the slowest, taking nearly 30 min to compress a typical image $\left(2048^{2}\right)$. Compression factors of 10:1 show little visual evidence of degradation, although they may have increased radiometric noise (in the $1-3$ data number (DN) range). Visual degradation of DC transformed images includes "blockiness" associated with the $16 \times 16$ pixel transform blocks that become obvious when high-frequency information is reduced in compression. Figure 3 shows some examples of applying various compression factors to a representative scene.

The MOC was designed and built by a team of university engineers, contracting companies of a variety of sizes, and consultants. Some of the major contributors are listed in Table 2. A more detailed description of the MOC hardware is given by Malin et al. [1991].

\section{Instrument Functions, Capabilities, and Constraints}

The Mars Observer orbit places some constraints on MOC operations. It is near polar (inclination $\sim 98^{\circ}$ ), near circular (380-km index altitude, with variations from a low of $360 \mathrm{~km}$ 




Fig. 6. Typical limb image at Mars Observer camera resolution (VO 088A14-17). 


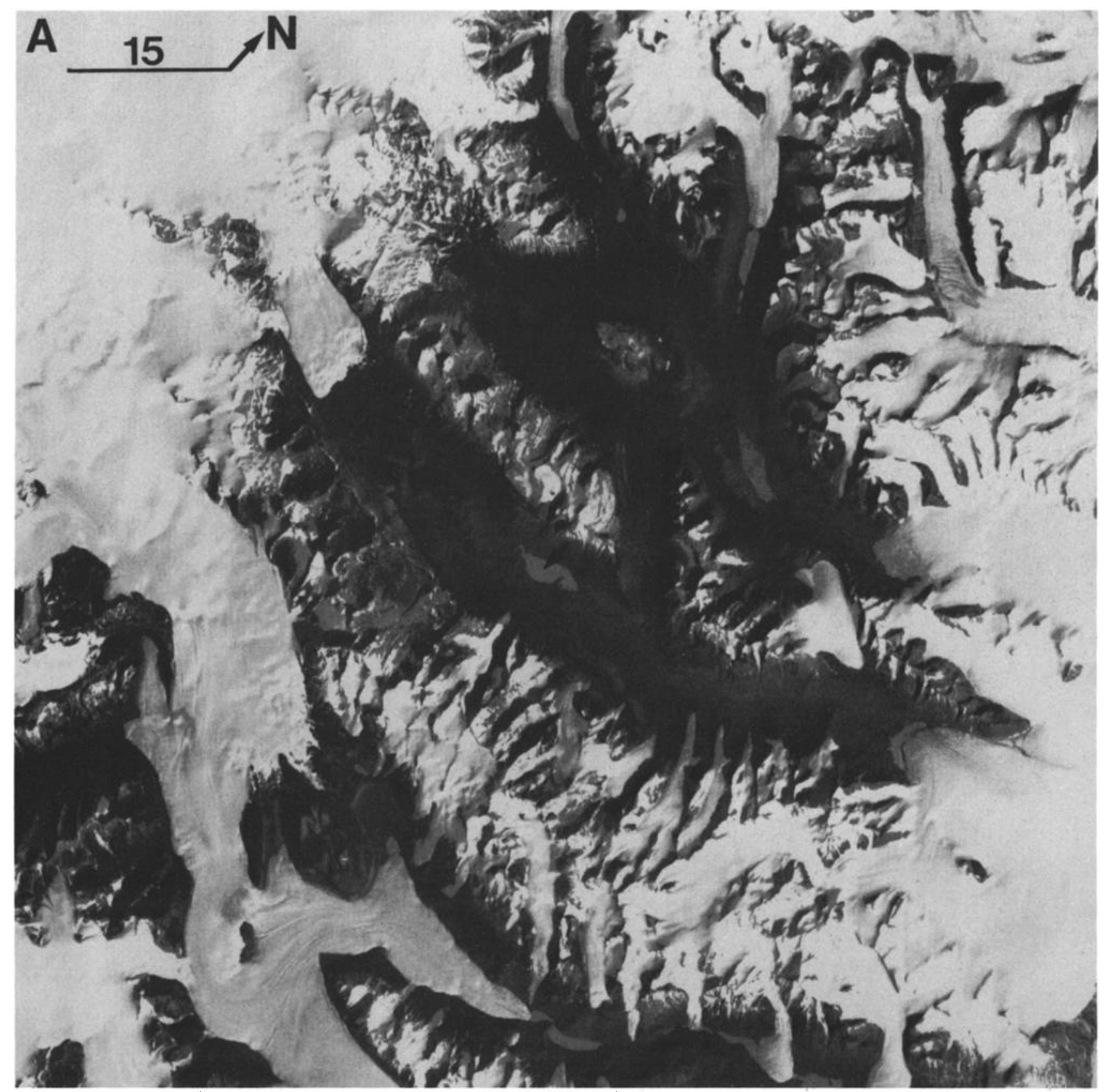

Fig. 7a. First of sequence of simulated Mars Observer camera high-resolution and context images for Lake Vanda, Central Wright Valley, Antarctica. This is the original Landsat scene at $80 \mathrm{~m} /$ pixel, roughly comparable to typical Viking coverage of Mars. Small black arrow indicates Lake Vanda, an ice-covered lake near center of frame seen at higher resolution in Figures $7 c$ and $7 d$.

to a high of $410 \mathrm{~km}$ ), and Sun synchronous (equator crossings occur at 0200 and 1400 local solar time (LST) and vary slowly between 0100 and 0300 and between 1300 and 1500 LST during the course of the mission). The descending node of the orbit occurs on the daylight side of the planet. The 118-min period gives rise to a $28.8^{\circ}$ offset in equator-crossing longitude between each orbit. For a more complete description of the orbit and other operational aspects of the Mars Observer mission, see Albee et al. [this issue].

Low-resolution observations can be made every orbit, such that in a single 24-hour period a complete global picture of the planet can be assembled at a resolution of at least 7.5 $\mathrm{km} /$ pixel. Of course, because the Mars Observer orbit is Sun synchronous, this global picture shows how each part of Mars appears at approximately 1400 LST. From an imaging perspective this global map also illustrates two principal limitations in the Mars Observer orbit: the absence of diurnal coverage (it samples Mars only at two times of day, and only one of those is during sunlit hours) and the poor illumination angle (chosen prior to the selection of a camera for the 


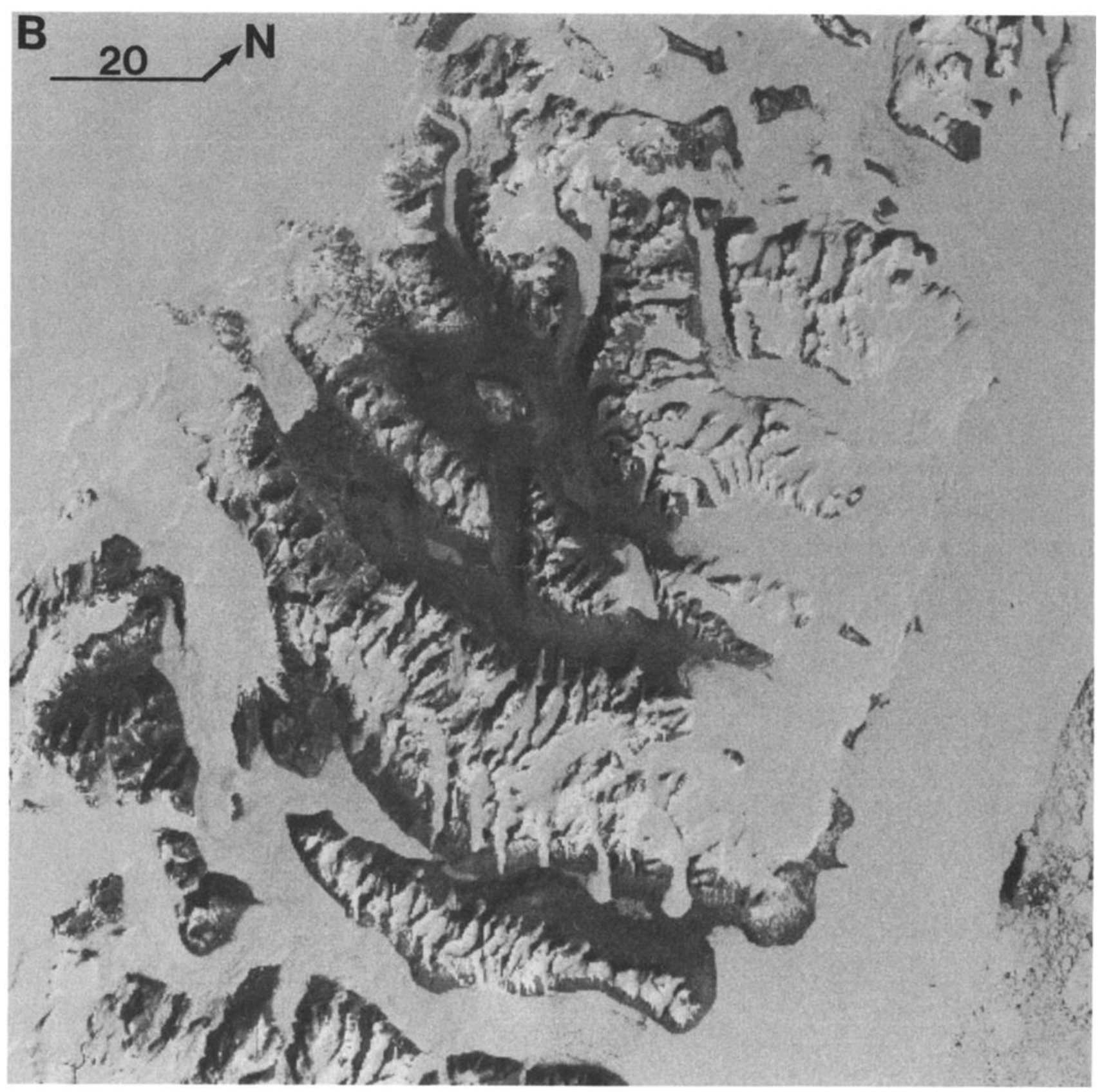

Fig. $7 b$. Mars Observer camera context frame resolution ( $\sim 240 \mathrm{~m} /$ pixel) version of same Landsat scene.

mission). Relief will be less apparent in images taken at low illumination angles near the equator, but at higher latitudes (i.e., nearer the terminator), relief shading will become more prominent. Shadows will be visible near the poles.

The fields of view of both the NA and WA cameras, the nature of the Mars Observer orbit, and specific aspects of the MOC design place certain constraints on viewing Mars. The width of MOC NA frames is limited by the camera field of view (FOV) to be $\sim 2.8 \mathrm{~km}$. Even if Mars Observer orbits were uniformly spaced, it would take over 600 days to overfly all of Mars. Given the 687-day nominal mission duration and the vagaries of the Mars Observer orbit, MOC will be fortunate to pass over each equatorial area once. Of course, at higher latitudes the number of opportunities to image a given location increases. Unfortunately, both the cross-track and along-track orbit prediction uncertainties are larger than the NA FOV; targeting a given feature will be a probabilistic activity. Contiguous "mosaics" of NA images are not possible. The WA FOV covers approximately 1300 $\mathrm{km}$ on the surface from nadir to each limb. At the equator, Mars Observer orbits are spaced about $1500 \mathrm{~km}$ apart; thus the limb on one orbit is at the nadir on the subsequent orbit and again at the limb on the orbit after that. There is therefore good overlap at the equator and excellent overlap closer to the poles.

MOC image sizes are determined by the camera FOV 


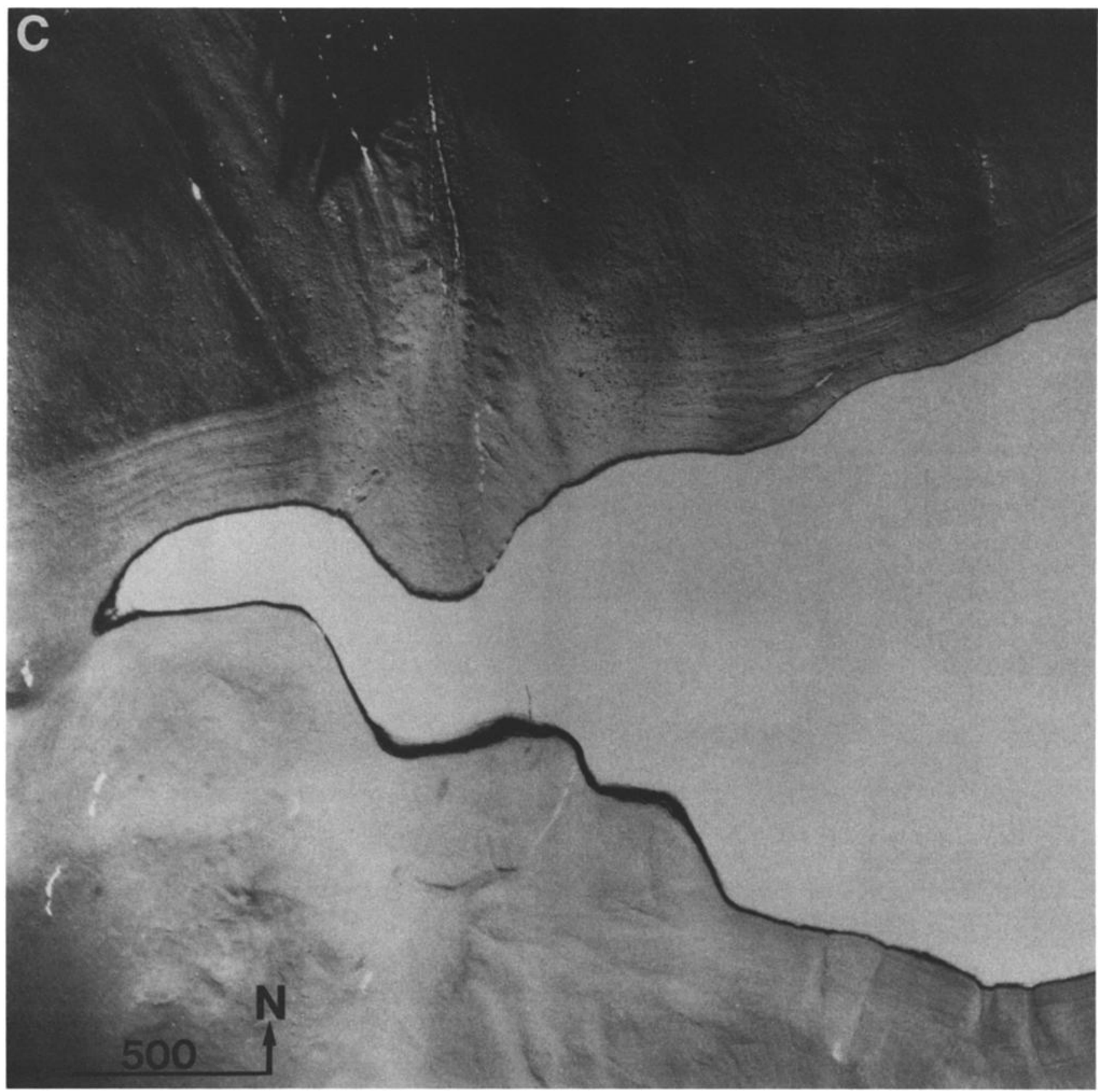

Fig. 7c. Aerial photograph of western tip of Lake Vanda, showing area approximately $3 \mathrm{~km} \times 3 \mathrm{~km}$ at $1.4 \mathrm{~m} / \mathrm{pixel}$. Small arrow in upper right indicates large boulder visible in Figure $7 d$.

(cross-track dimension, as noted above) and by the size and utilization of the DRAM buffer (along track). By using real time compression it is possible to acquire a NA image longer than the orbit determination along-track uncertainty. However, other contents of the buffer may prevent its use in this manner. Buffer space is thus an important resource that requires close management. For this reason, MOC images can vary in size and compression factor. By using the NA camera, areas ranging from $2.8 \mathrm{~km} \times 2.8 \mathrm{~km}$ to $2.8 \mathrm{~km} \times$ $25.2 \mathrm{~km}$ (depending on available buffer memory) can be imaged at about $1.4 \mathrm{~m} / \mathrm{pixel}$. Additionally, lower-resolution pictures (to a lowest resolution of about $11 \mathrm{~m} / \mathrm{pixel}$ ) can be acquired by pixel averaging. Contingent as well upon available power, these images can be much longer, ranging up to $2.8 \times 500 \mathrm{~km}$ at $11 \mathrm{~m} /$ pixel. Similar limitations influence the use of the WA cameras, and the same compression and sampling flexibility exists to address these limitations.

MOC data rate allocations change substantially over the course of the Mars Observer mission. MOC has been allocated data for each of the three record rates and the real-time rate. These vary from $0.7 \mathrm{kbit} / \mathrm{s}$ during the lowest record rate to $9 \mathrm{kbit} / \mathrm{s}$ during the highest record rate, and $29 \mathrm{kbit} / \mathrm{s}$ during real-time transmissions. These rates permit the daily transmission of roughly 2,4 , and 8 uncompressed $2048 \times 2048$ 




Fig. 7d. Enlargement of digitized aerial photograph showing northeast portion of aerial photograph $(512 \times 512$ pixel area enlarged, resolution is $1.4 \mathrm{~m} / \mathrm{pixel}$ ). Arrow points to large boulder visible in Figure $7 c$.

images during "record only" days and, on the average of once every 3 days, 14 such images during an 8-hour real-time pass. These numbers can be larger or smaller, depending on the compression factors used and the resolution of the global map. MOC is capable of simultaneously sending data to both the record and real-time streams and is further capable of matching any data rate available on board the spacecraft.

MOC is fixed to the nadir panel of the spacecraft. It has no independent pointing capability. Once in the mapping orbit, it cannot view Phobos or Deimos, nor can it view stars for calibration.

\section{OPERATIONS}

\section{Types of Observations}

MOC is virtually unlimited in the manner it observes Mars. For the purpose of this discussion it may be convenient for the reader to think in terms of three types of observations characterized by resolution and time coverage: global (monitoring), regional (mapping), and high resolution (sampling).

Global (monitoring). This type of observation is distinguished by low resolution acquired on a daily basis over the 


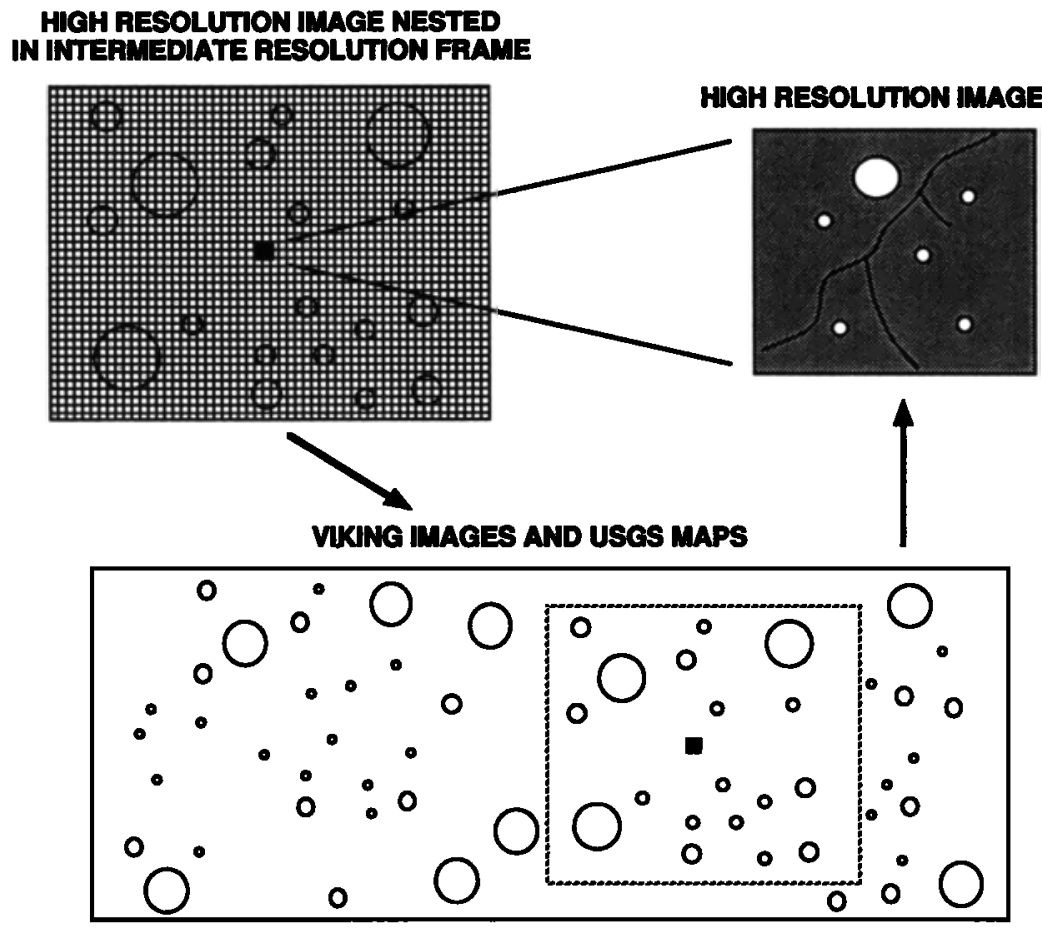

Fig. 8. Use of wide angle "context" image to determine location of narrow-angle image.

course of the entire mission. The major objectives of this type of observation might include (1) monitoring global atmospheric phenomena and (2) monitoring polar cap phenomena over the entire polar regions.

In both cases the monitoring must be carried out on a variety of time scales ranging from daily to seasonal. On any given day, perhaps $15-20 \%$ of MOC observations may be devoted to global assessments.

Global monitoring uses the low-resolution capability of the MOC instrument to systematically accumulate a global picture of the surface and atmosphere of Mars, at about $7.5 \mathrm{~km}$ resolution, at $1400 \mathrm{LT}$ (Figure 4). In resolution and viewing geometry, these images will be very similar to NOAA (TIROS) satellite images of the Earth. Global monitoring data might be used to extract information about atmospheric circulation, water vapor content, and dust activity from observations of cloud morphology, motion, and variability as well as from changes in surface wind-related features.

Regional (mapping). Regional observations may be acquired by the wide-angle optical systems to provide higherresolution, subglobal (regional) views of the surface and atmosphere of Mars, comparable to Viking "intermediate mapping" frames. There are two general types of regional targets: those to be imaged several times, in a program to monitor changes, and those to be imaged only once, for example, to characterize changes since the Mariner 9 or Viking missions.

Example objectives of this part of the MOC investigation are (1) observing selected atmospheric phenomena at moderate resolution, (2) observing changes in selected surface features during the mission, and (3) evaluating the state of Mars relative to that recorded by earlier missions.

The large field of view of the wide-angle system permits daily repeat coverage. The size of the image returned is determined by the data buffer, but a typical image might be $500 \mathrm{~km}$ wide by $1500 \mathrm{~km}$ long (e.g., Figure 5). Spatial resolution of these data can be as high as $230 \mathrm{~m} /$ pixel at the nadir, diminishing to about $1.5 \mathrm{~km} / \mathrm{pixel}$ at the limb (Figure 6).

Depending on the orbital ground track, as much as $25-40 \%$ of a given day's observations may be at this intermediate resolution.

High resolution (sampling). Only a very small percentage of Mars can be imaged at the intrinsic resolution of the narrow-angle camera, since it has such a very small field of view $\left(0.44^{\circ}\right.$ or about $3 \mathrm{~km}$ across at the nominal spacecraft altitude) and the data rate is so much higher than can be returned to Earth (by about a factor of 10,000). These factors, and orbital position uncertainties, limit access to high-resolution observations of any specific location on Mars to once over the entire mission. Thus the NA camera is likely to be used to "sample" areas rather than to "map" them. In order to determine the exact position of the high-resolution samples, about 480 lines of intermediate resolution data are acquired simultaneously with each highresolution image, providing a "context" image for feature correlation (Figures 7, 8, and 9).

Samples of the planet at high resolution can address such varied objectives as (1) examining surface/atmospheric interactions at high resolution, (2) studying geology at a scale that links Viking Orbiter and Lander data, and (3) observing surface physical properties for correlation with other remote sensing data.

Narrow-angle camera observations will vary with season and atmospheric conditions. During clear periods, NA acquisitions may dominate the data return, while during dust storms few if any NA images will be taken.

\section{Calibration}

MOC is designed primarily to acquire images of acceptable visual quality. In order to meet schedule and cost 


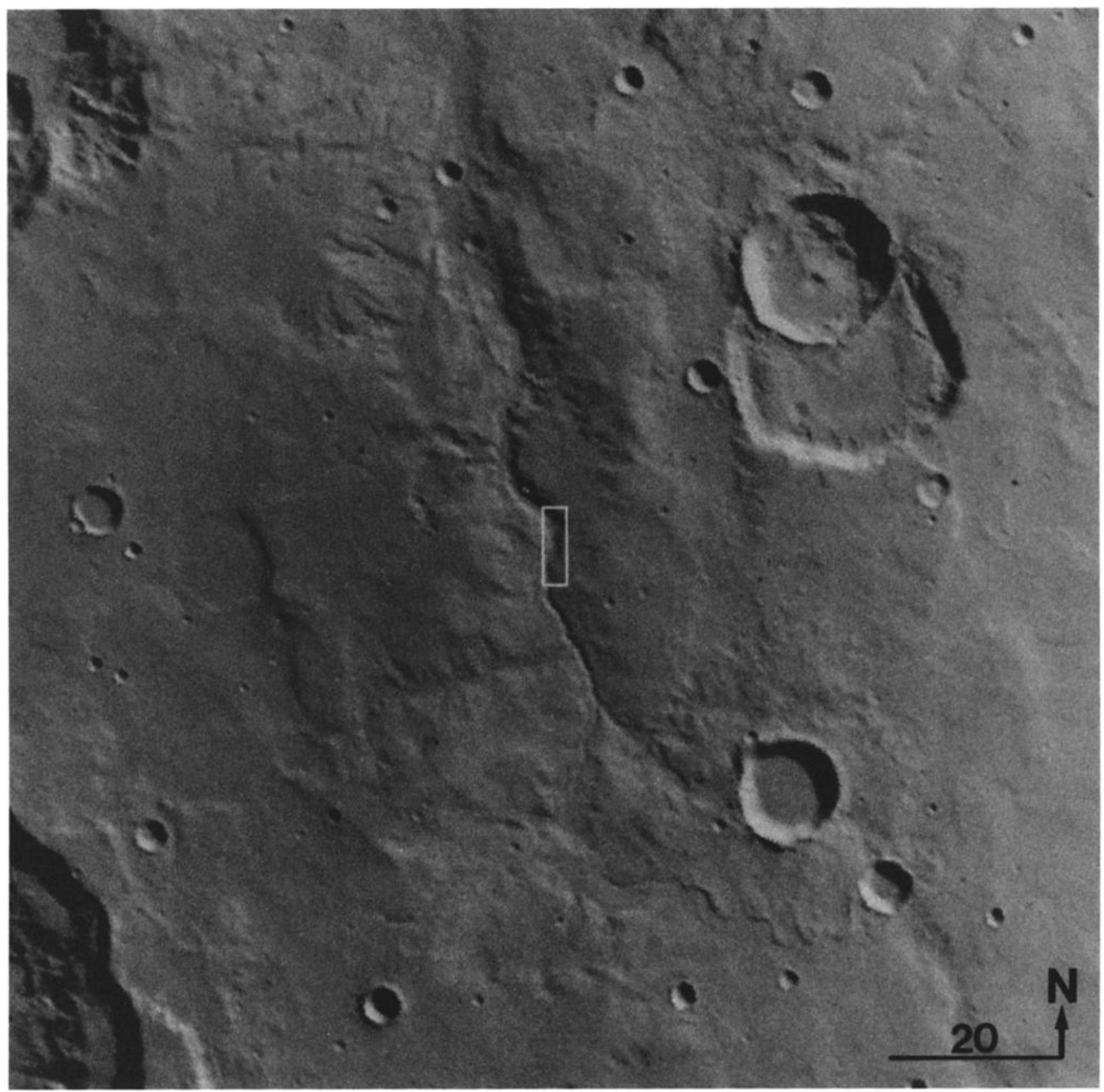

Fig. 9. Example "context" frame with location of narrow-angle image outlined (portion of VO 084A10).

constraints, its calibration is necessarily limited. Owing to its nadir-fixed orientation, MOC cannot view any spacecraftmounted calibration targets. The Mars Observer Project has no plans to point the spacecraft off nadir to allow observations of potential calibration sources such as Phobos and Deimos, stars, or other astronomical objects. A limited set of prelaunch measurements have been acquired to characterize the MOC photometric performance. However, occasional coordinated observations with TES and PMIRR, especially during regional or global dust storms when the atmosphere obscures the surface and might present a relatively featureless target, will be the only way to assess the MOC photometric performance. Geometric performance (both MTF and distortion) of the optics were measured during their fabrication, and a limited set of measurements, again to characterize the instrument performance, were made just prior to instrument delivery. These characteristics will be available as part of the instrument description file in the Planetary Data System.

The MOC has a limited ability to focus its NA camera. An assessment of focus will be made from the 24-hour transition orbit into which Mars Observer first inserts, using images of stars.

\section{Sequence Design}

The Mars Observer mission is predicated on a remote operations plan in which individual principal investigators 
(PI), team leaders (TL), and interdisciplinary scientists (IDS) are completely responsible for the generation of observational sequences at their own home institutions. For much of the payload, sequences involve mostly repetitive activities (such as pointing mirror commands), but for MOC, considerable sequence flexibility is required to meet its observational goals. However, under the guidelines established by the Mars Observer Project, such flexibility must be transparent to the mission operations team at JPL, as the mission is planned to be run from a set of sequences predefined before launch. Presently, the Mars Observer Project plans to construct 56- and 28-day sequences, transmitted in small segments sufficiently often to insure at least 3 days of operational commands in residence on the spacecraft. In order to maximize its ability to image specific features on Mars, MOC will uplink sequences relative to positions based on longterm orbit predictions and modify these sequences on the basis of updated orbit information between 1 and 3 days prior to data acquisition.

MOC sequence design is based on the desire to image two types of targets: those that are time-independent and those that are variable. In both cases the targets will be entered into the MOC operational data base. Targets will be identified by position on Mars; additional ancillary data necessary to specify most of the "event"' file information about each observation (e.g., longitude and latitude of target, type of target, objective of observations, etc.) will be included with each data base entry. For each target an operational strategy will be developed, including, for example, specification of image size and shape optimized for science coverage and repeat cycle intervals for WA regional coverage. Targets will be sorted by occurrence along the predicted orbits. Initial sequences of accessible targets will be created from the list of targets that occur along the predicted orbits and within a tolerance of possible deviations from those orbits. The sequence will then be evaluated against the available downlink data rate. Representative, multiday sequences will then be produced and uplinked to the spacecraft. These sequences will be reevaluated whenever better orbit predictions are available, and necessary changes will be uplinked.

\section{Data Records and Products}

As with sequence planning and instrument operation, data analysis will also be the sole responsibility of the PI, TL, and IDS. Thus MOC images will be reconstructed from raw data at a facility dedicated to MOC operations and data analysis. On the basis of the present data rate allocations, MOC will return approximately $3.5 \times 10^{11}$ bits during the 687-day nominal mission. As noted above, the MOC data can be compressed between 1.5 and 2.5 times without loss and up to 20-30 times with acceptable loss. A reasonable assumption is that the MOC data will be compressed, on average, about 5 times, so the total data output when decompressed will be about $2 \times 10^{12}$ bits. The MOC investigation is not currently funded to "decompress" its data for return to either the Mars Observer Project Data Base or the Planetary Data System. The plan is to leave the data in their compressed form and to provide as part of the experiment data record (EDR) the decompression algorithms, prelaunch calibration files, and available supplementary information (e.g., planet and spacecraft ephemeris, etc.). The exception to this plan is the production of a daily global image for use by the Project
Science Group in mission and science planning and data analysis. MOC reduced data records will not be produced as separate entities: rather, refined ancillary information and/or calibration data will be appended to the EDR.

\section{Mars Balloon Relay}

In mid-1987, J. Blamont of the French Centre National d'Etudes Spatiales (CNES) proposed that a system be devised wherein data from French balloons associated with the Soviet Mars '94 mission be received and transmitted to Earth by Mars Observer. Owing to its unique data handling and storage capabilities, MOC has become the enabling link between the French-built antenna and receiver and the Mars Observer spacecraft data system. During the last month of the Mars Observer nominal mission the two balloons will return approximately 3.5 Gbits through the MOC data system, mostly in the form of images from each balloon's cameras. Additionally, other surface-deployed systems are under study by the Soviets and may also take advantage of the Mars Observer relay link.

Acknowledgments. The Mars Observer camera is the first PI camera developed for a planetary mission in 25 years. The team expresses its appreciation to W. Quaide for his support in the premission instrument definition period and B. Edelson for selecting the camera despite concerns over the costs of imaging experiments. W. Purdy, D. Evans, T. Thorpe, A. Albee, F. Palluconi, and especially G. Reisdorf have provided strong support for the camera since the inception of the Mars Observer Project. The MOC would not exist without the efforts of N. Evans and D. Carter (Califomia Institute of Technology), D. Michna (Arizona State University), and G. Robinson (Jet Propulsion Laboratory). M.C.M. (principal investigator) acknowledges premission support through Planetary Instrument Definition and Development Program (PIDDP) grants NAGW-524 and NASW-4075, and Mars Observer JPL contract 957575.

\section{REFERENCES}

Albee, A. L., R. E. Arvidson, and F. D. Palluconi, Mars Observer mission, J. Geophys. Res., this issue.

Baker, V., Paleohydraulic interpretation of Quaternary alluvium near Golden, Colorado, Quat. Res., 4, 94-112, 1974.

Baker, V., The Channels of Mars, 198 pp., University of Texas Press, Austin, 1982.

Belton, M. J. S., G. Smith, G. Schubert, and A. D. Del Genio, Cloud patterns, waves and convection in the Venus atmosphere, J. Atmos. Sci. 33, 1394-1417, 1976.

Blasius, K., J. Cutts, J. Guest, and H. Masursky, Geology of Valles Marineris: First analysis of imaging from the Viking orbiter primary mission, J. Geophys. Res., 82, 4067-4091, 1977.

Briggs, G., K. Klaasen, T. Thorpe, J. Wellman, and W. Baum, Martian dynamical phenomena during June-November $1976, J$. Geophys. Res., 82, 4121-4149, 1977.

Briggs, G., W. Baum, and J. Barnes, Viking Orbiter imaging observations of dust in the Martian atmosphere, J. Geophys. Res., 84, 2795-2820, 1979.

Carr, M., Volcanism on Mars, J. Geophys. Res., 78, 4049-4062, 1973.

Carr, M., Formation of Martian flood features by release of water from confined aquifers, J. Geophys. Res., 84, 2995-3007, 1979.

Carr, M., K. Blasius, R. Greeley, J. Guest, and J. Murray, Observations on some Martian volcanic features as viewed from the Viking orbiters, J. Geophys. Res., 82, 3985-4015, $1977 a$.

Carr, M., L. Crumpler, J. Cutts, R. Greeley, J. Guest, and H. Masursky, Martian impact craters and emplacement of ejecta by surface flows, J. Geophys. Res., 82, 4055-4065, $1977 b$.

Christensen, P., Martian dust mantling and surface composition: Interpretation of thermophysical properties, J. Geophys. Res., 87, 9985-9998, 1982. 
Christensen, P., Eolian intracrater deposits on Mars: Physical properties and global distribution, Icarus, 56, 496-518, 1983.

Cutts, J. A., Nature and origin of layered deposits of the Martian polar regions, J. Geophys. Res., 79, 4231-4249, 1973.

Cutts, J. A., K. R. Blasius, and K. D. Pang, Polar layered deposition on Mars-New evidence on their mode of formation (abstract), Eos Trans. $A G U, 59(4), 313,1978$.

Cutts, J. A., K. R. Blasius, and W. J. Roberts, Evolution of Martian polar landscapes: Interplay of long-term variations in perennial ice cover and dust storm intensity, J. Geophys, Res., 84, 29752994, 1979.

French, R., P. Gierasch, B. Popp, and R. Yerdon, Global patterns in cloud forms on Mars, Icarus, 45, 468-493, 1981

Gierasch, P., P. Thomas, R. French, and J. Veverka, Spiral clouds on Mars: A new atmospheric phenomenon, Geophys. Res. Lett., 6, 405-408, 1979.

Greeley, R., and J. D. Iversen, Wind as a Geological Process on Earth, Mars, Venus and Titan, 333 pp., Cambridge University Press, New York, 1985.

Greeley, R., J. D. Iversen, J. B. Pollack, N. Udovich, and B. White, Wind tunnel simulations of light and dark streaks on Mars, Science, 183, 847-849, 1974.

Hulme, G., The interpretation of lava flow morphology, Geophys. $J$. R. Astron. Soc., 39, 361-383, 1974.

Ingersoll, A. P., R. F. Beebe, J. L. Mitchell, G. W. Garneau, G. M. Yagi, and J. P. Muller, Interaction of eddies and mean zonal flow on Jupiter as inferred from Voyager 1 and 2 images, J. Geophys. Res., 86, 8733-8743, 1981.

Iversen, J. D., and R. Greeley, Martian crater dark streak lengths: Explanation from wind tunnel experiments, Icarus, 58, 358-362. 1984.

Jakosky, B., The seasonal cycle of water on Mars, Space Sci. Rev., $41,131-200,1985$.

Kahn, R., The spatial and seasonal distribution of Martian clouds and some meteorological implications, J. Geophys. Res., 89, 6671-6688, 1984.

Limaye, S. S., and V. E. Soumi, Cloud motions on Venus: Global structure and organization, J. Atmos. Sci., 38, 1220-1235, 1981.

Limaye, S. S., H. E. Revercomb, L. A. Sromovsky, R. J. Krauss, D. A. Santek, and V. E. Soumi, Jovian winds from Voyager 2, I, Zonal mean circulation, J. Atmos. Sci., 39, 1413-1432, 1982.

Lucchitta, B., Morphology of chasma walls, Mars, J. Res. U.S. Geol. Surv., 6, 651-662, 1978.

Malin, M., Nature and origin of intercrater plains on Mars, Ph.D. dissertation, 186 pp., Calif. Inst. of Technol., Pasadena, 1976.

Malin, M., G. E. Danielson, M. A. Ravine, and T. A. Soulanille, Design and development of the Mars Observer Camera, Int. J. Imaging Syst. Technol., 3, 76-91, 1991.

Mars Channel Working Group, Channels and valleys on Mars, Geol. Soc. Am. Bull., 94, 1035-1054, 1983.

McCauley, J., Geologic map of the Coprates quadrangle of Mars, U.S. Geol. Surv. Misc. Invest. Map, I-896, 1978.

Milton, D., Water and processes of degradation in the Martian landscape, J. Geophys. Res., 78, 4037-4047, 1973.

Moore, H., D. Arthur, and G. Schaber, Yield strengths of flows on the Earth, Mars, and Moon, Proc. Lunar Planet. Sci. Conf., 9th, 3351-3378, 1978 .

Mouginis-Mark, P., Martian fluidized crater morphology: Variations with crater size, altitude, and target material, J. Geophys. Res., 84, 8011-8022, 1979.

Murray, B. C., L. A. Soderblom, J. A. Cutts, R. P. Sharp, D. J. Milton, and R. B. Leighton, Geological framework of the south polar region of Mars, Icarus, 17, 328-345, 1972.

Newman, M., G. Schubert, A. J. Kliore, and I. R. Patel, Zonal winds from the middle atmosphere of Venus from Pioneer Venus radio occultation data, J. Atmos. Sci., 41, 1901-1913, 1984.
Peterfreund, A., and H. Kieffer, Thermal infrared properties of the Martian atmosphere, 3, Local dust storms, J. Geophys. Res. 84, 2853-2863, 1979.

Peterson, C., A secondary origin for the central plateau of Hebes Chasma, Proc. Lunar Planet. Sci. Conf., 12B, 1459-1471, 1981.

Pieri, D., Martian valleys: Morphology, distribution, age, and origin, Science, 210, 895-897, 1980.

Pirraglia, J., Martian atmospheric lee waves, Icarus, 27, 517-530, 1976.

Pollack, J., R. Haberle, R. Greeley, and J. Iverson, Estimate of the wind speeds required for particle motion on Mars, Icarus, 29, 395-417, 1976.

Pollack, J., D. Colburn, F. Flasar, R. Kahn, C. Carlston, and D. Pidek, Properties and effects of dust particles suspended in the Martian atmosphere, J. Geophys. Res., 84, 2929-2945, 1979.

Pollack, J., C. Leovy, P. Greiman, and Y. Mintz, A martian general circulation experiment with large topography, J.Atmos. Sci., 38, 3-29, 1981.

Schubert, G., General circulation and the dynamical state of the Venus atmosphere, in Venus, edited by D. M. Hunten et al., pp. 681-765, University of Arizona Press, Tucson, 1983.

Sharp, R., Mars: Troughed terrain, J. Geophys. Res., 78, 40634072, 1973.

Sharp, R., and M. Malin, Channels on Mars: Geol. Soc. Am. Bull., 86, 593-609, 1975.

Solar System Exploration Committee, Planetary Exploration Through the Year 2000: A Core Program, 167 pp., U.S. Government Printing Office, Washington, D.C., 1983.

Thomas, P., Martian intracrater splotches: Occurrence, morphology, and colors, Icarus, 57, 205-227, 1984.

Thomas, P., and P. J. Gierasch, Dust devils on Mars, Science, 230 175-177, 1985.

Thomas, P., and J. Veverka, Seasonal and secular variations in wind streaks on Mars, J. Geophys. Res., 84, 8131-8146, 1979.

Thomas, P., J. Veverka, and R. Campos-Marquetti, Frost streaks in the south polar cap of Mars, J. Geophys. Res., 84, 4621-4633, 1979.

Thomas, P., J. Veverka, S. Lee, and A. Bloom, Classification of wind streaks on Mars, Icarus, 45, 124-153, 1981.

Tillman, J., R. Henry, and S. Hess, Frontal systems during passage of the Martian North Polar Hood over the Viking Lander 2 site prior to the first 1977 dust storm, J. Geophys. Res., 84, 2947-2955, 1979.

Toon, O., J. Pollack, W. Ward, J. Burns, and K. Bilski, The astronomical theory of climate change on Mars, Icarus, 44 , 552-607, 1980.

Veverka, J., P. Gierasch, and P. Thomas, Wind streaks on Mars Meteorological control of occurrence and mode of formation, Icarus, 45, 154-166, 1981.

Zurek, R., Martian great dust storms: An update, Icarus, 50, 288-310, 1982.

G. E. Danielson and A. P. Ingersoll, Division of Geological and Planetary Sciences, California Institute of Technology, Pasadena, CA 91125 .

M. C. Malin, Malin Space Science Systems, Incorporated, 3535 General Atomics Court, Suite 250, San Diego, CA 92121.

M. A. Ravine and T. A. Soulanille, Altadena Instruments Corporation, Pasadena, CA.

J. Veverka, Center for Radiophysics and Space Physics, Space Sciences Building, Cornell University, Ithaca, NY 14853.

(Received May 6, 1991;

revised February 10, 1992; accepted February 12, 1992.) 